\title{
Oil Price And Stock Market Linkages In A Small And Oil Dependent Economy: The Case Of Greece
}

\author{
Katrakilidis Constantinos, Aristotle University of Thessaloniki, Greece \\ Lake Andreas Ektor, Aristotle University of Thessaloniki, Greece \\ Mardas Dimitrios, Aristotle University of Thessaloniki, Greece
}

\begin{abstract}
We investigate the dynamic linkages between oil prices and the stock market behaviour in a small and oil dependent economy. Particularly, we analyse empirically the relationships among stock market returns, the volatility of the stock market index, the oil price and the volatility of oil price in Greece. We employ VAR modelling in conjunction with Granger-causality tests. Contrary to the majority of the internationally reported evidence, our findings show the existence of significant positive causal effects from oil price changes on the stock market.
\end{abstract}

Keywords: Oil Price, Stock Market, Volatility,Vector Autoregressions, Granger Causality, GARCH

\section{INTRODUCTION}

$\mathcal{O}$ ver the recent decades, oil price has had a prominent role in modulating the economic and political situation in the developed countries. The oil price crises of the 1970's have created major aggregate supply shocks in the world economy. Indeed, the price per barrel increased from US\$ 2.45 in 1972 to US\$ 11.25 in 1974 and it reached US\$ 31.5 in 1980 (see Figure 1, Appendix). During the same period, the agreements of the "Kennedy Round" negotiations on trade liberalization had been fulfilled and any increases of oil prices were followed by new efforts for trade liberalization. A new round of negotiations started in the middle of the oil crisis of that decade, known as the "Tokyo Round". In the context of this round, by the end of 1986, trade in industrial goods became free of tariffs and non-tariff barriers. However, a number of exceptions remained. The remaining restrictions on trade of industrial products and the abolition of the existing trade restrictions on agricultural products and services were the main subject of the "Uruguay Round" negotiations. These efforts aimed, inter alia, to counterbalance the excepted negative impact of the oil price shocks on the world trade flows and hence on profits and stock markets.

The relevant international literature has attempted, primarily, to identify the effects of changes in international oil price on certain macroeconomic variables, such as GDP growth rates, inflation and exchange rates and henceforth the performance of the local stock markets (Hamilton, 1983; Mork, 1989 among others). A strand within this literature has been devoted to the study of the relationship between oil market and stock markets with the majority of the literature finding evidence for a negative relationship between oil price and stock market returns (Jones and Kaul, 1996; Sandorsky, 1999; Ciner, 2001).

Building on this literature we examine the effects of oil price changes on the stock markets in the small open Greek economy for which not much research has been conducted on this specific area. An additional motivation for our effort is that in the examined period (01/01/2004 - 31/12/2006) we had irregularly high oil prices while at the same time the Greek stock market was facing a bubble effect. Moreover, the fact that the Greek stock index is heavily composed of oil related companies or oil holding companies, may produce interesting results and the findings will be useful in the determination of the policy that should be followed in small and oil dependent economies. Depending on the findings, the regulator may consider stock market intervention policies that will support the listed companies and the investment community when needed or may focus on precautionary measures in order to minimize the effects in the economy in the case of unpredicted oil price movements. 
This paper contributes to the literature by shedding light on the above considerations. We apply vector autoregressive (VAR) methodology and Granger-causality analysis to consider the possible linkages between the Greek stock market returns, the international oil price, and their volatilities respectively. We quantify the volatilities of these two variables quantified by means of EGARCH modeling.

The rest of the paper is organized as follows: The next section presents a review of the relevant literature. Section 3, presents the data and the empirical results. Finally, section 4, summarizes and concludes.

\section{LITERATURE REVIEW}

Despite the fact that most empirical studies focus on the relation between economic activity and oil price index changes, it is staggering that only few studies have been conducted on the relationship between financial markets and oil price shocks. If oil price affects real GNP, it will affect earnings of companies for which oil is a direct or indirect operational cost. Thus, an increase in oil price will cause expected earnings to decline, and this will bring about an immediate decrease in stock price if the stock market efficiently capitalizes the cash flow implications of the oil price increase. Mork, Olsen and Mysen (1994) extend these findings to six other industrialized countries: Japan, Germany, Canada, France, the U.S. and Norway. They show that oil price shocks affect the GDP in all these countries, although the effects are stronger for the U. S. Japan and Norway.

Jones and Kaul (1992), examine the effect of the oil price on the stock prices. They detect significant effect of oil price on aggregate real stock returns, including a lagged effect, for the period 1947 to 1991 . Their paper has a macroeconomic focus, using quarterly data and employing the Producer Price Index for fuels to proxy the oil price index. Jones and Kaul (1996), use quarterly data to test whether the reaction of international stock markets to oil shocks can be justified by current and future changes in real cash flows and hence the changes in expected returns. Using a standard cash-flow dividend valuation model they find that the reaction of Canadian and U.S. stock prices to oil price shocks can be completely accounted for the impact of these shocks on the real cash flows. The results for Japan and the UK are, however, not as strong. Papapetrou (2001) attempts to shed light into the dynamic relationship among oil price, real stock prices, interest rates, real economic activity and employment in Greece, by employing a multivariate vector autoregression (VAR) approach. The empirical evidence suggests that oil price changes affect real economic activity and employment while stock returns do not lead to changes in real activity and employment. Oil price is important in explaining stock price movements. The results show that a positive oil price shock depresses real stock returns. Huang, Masulis and Stoll (1996) investigate the impact of oil price shocks on the U.S. equity market from a financial markets perspective. Within the framework of a vector autoregression (VAR) model, they examine dynamic interactions between daily oil futures returns and stock returns. Moreover, a study by Maghyereh (2004) reveals that oil price shocks have no important significance on stock index returns. He examines the dynamic linkages between crude oil price shocks and stock market returns in 22 emerging economies. The vector autoregression (VAR) analysis is carried out by using daily data covering the period between 1/1/1998 and 31/4/2004. Inconsistent with prior research on developed economies, the findings imply that oil shocks have no significant impact on stock index returns in emerging economies. The results also suggest that stock market returns in these economies do not rationally signal shocks in the crude oil market. Some studies have also dealt with the lead-lag relationship between spot and futures for the oil market. Bopp and Sitzer (1987) tested the hypothesis that futures prices are good predictors of spot prices in the heating oil market, and found that, even when crude oil price, inventory levels, weather, and other important variables were accounted for, futures prices still have a significant positive contribution in describing past price changes. Concerning the oil price volatility, most studies have attempted to model the oil price shocks by using GARCH models. Hwang, Yang, Huang and Ohta (2004), after modelling the oil price volatility with the aid of a GARCH model, they constructed a VAR model and examined the Granger Causal effects between oil price volatility, exchange rates, stock market returns, inflation and industrial production. They focus on Canada, Italy, Germany, the U.S, the U.K. and Japan. They concluded that the volatility of oil price changes leads to negative stock returns in three out of six cases while it affects the industrial production in just two cases. Sadorsky (1999) suggests that there is an interaction between oil price, oil price volatility and stock market returns. He shows that oil price movements are important in explaining movements in the stock returns in the U.S. market. 
Hamilton (1983) argues that oil price shocks were responsible, at least partly, for every U.S. recession in the post-World War II period. Many other studies, such as Loungani (1986), Gisser and Goodwin (1986), Mork (1989) and Lee, Ni and Ratti (1995), report similar conclusions, using different data and econometric approaches.

\section{DATA AND EMPIRICAL RESULTS}

For the empirical analysis we use daily data from Bloomberg covering the period between 2004 and 2006. In particular, we use the General Index of the ASE and the crude oil price index. Both are used in logarithmic form and are denoted as LSP and LOP respectively. Numerous studies have provided evidence that the variance of the stock and oil price returns are time varying and heteroscedastic (Mandelbort 1963, Fama 1965, Bollesev, Chou and Kroner, 1992). This implies that if one ignores the time dependent nature of volatility then any inference regarding the impact on volatility may be misleading. Thus, the first step in the empirical analysis is modelling the volatility of the stock market returns and the oil price index returns. A particularly important preliminary problem is the choice of the appropriate methodology to estimate the market volatility since estimates are highly sensitive to the measure of volatility adopted. The ARCH/GARCH modelling techniques are used by the majority of the researchers as the most adequate measure of volatility and hence the same methodology is adopted in this study.

Nelson (1991), proposes the exponential GARCH (EGARCH) model as an extended version of the GARCH model. The EGARCH model allows for asymmetry in the responsiveness of the volatility variables to the sign of the shocks. Secondly, the EGARCH model, specified in logarithms, does not impose the non-negativity constraints on parameters. Finally, the use of logarithms hampers the effects of outliers on the estimation results. We employed log likelihood ratio tests on a EGARCH $(\mathrm{p}, \mathrm{q})$ model in order to specify the EGARCH representation of the conditional variance of the stock price returns and the oil price returns at time $i$ as:

$$
\operatorname{Logh}_{i}^{2}=\beta_{0}+\beta_{1}\left|\varepsilon_{i-1}\right| / h_{i-1}+\beta_{2} \varepsilon_{i-1} / h_{i-1}+\beta_{3} \operatorname{Logh}_{i-1}^{2}
$$

It should be mentioned that $\left|\varepsilon_{\mathrm{i}-1}\right| / \mathrm{h}_{\mathrm{i}-1}, \varepsilon_{\mathrm{i}-1} / \mathrm{h}_{\mathrm{i}-1}$ and the log of the lagged value of the conditional variance $\left(\mathrm{h}_{\mathrm{i}}^{2}\right)$ is used to explain the behaviour of the conditional variance which hereafter will be denoted by VARLS and VAROIL for the stock market returns and the oil price returns respectively.

More specifically, we constructed our volatility proxies using the conditional variance of returns, which has been retrieved from the maximum likelihood estimation of an $\mathrm{EGARCH}(0,1)$.

$$
\begin{aligned}
& \operatorname{DLS}_{\mathrm{i}}=\alpha_{0}+\sum_{i=1}^{p} \alpha_{\mathrm{i}} \mathrm{DLS} S_{\mathrm{i}-1} \varepsilon_{\mathrm{s}, \mathrm{i}}, \quad \varepsilon_{\mathrm{i}} \mid\left(\varepsilon_{\mathrm{i}-1}, \varepsilon_{\mathrm{i}-2}, \ldots\right) \sim \mathrm{N}\left(0, \mathrm{~h}_{\mathrm{i}}\right) \\
& \mathrm{DLOP}_{\mathrm{i}}=\alpha_{0}+\sum_{i=1}^{p} \alpha_{\mathrm{i}} \mathrm{DLOP}_{\mathrm{i}-1} \varepsilon_{\mathrm{p}, \mathrm{i}}, \quad \varepsilon_{\mathrm{i}} \mid\left(\varepsilon_{\mathrm{i}-1}, \varepsilon_{\mathrm{i}-2}, \ldots\right) \sim \mathrm{N}\left(0, \mathrm{~h}_{\mathrm{i}}\right)
\end{aligned}
$$

where DLS denotes the stock market returns, $\varepsilon$ is the error term and equation (2) denotes the conditional mean equation of the returns while DLOP denotes the oil price returns, $\varepsilon$ is the error term and equation (3) denotes the conditional mean equation of the returns.

It should also be noted that we have used daily continuing compounded returns. The calculation for the stock market and the oil price returns are presented in equation (4) and (5) respectively.

$$
D L S_{i}=\log \left(L S_{i} / L S_{i-1}\right)
$$

and 


$$
D L O P_{i}=\log \left(L O P_{i} / L O P_{i-1}\right)
$$

Both E-GARCH models were specified on the grounds of the general to specific approach and using the standard statistical diagnostics. The testing procedure used lags of up to 24 days. The estimates of the above EGARCH model are presented in Table 1 and Table 2 in the appendix.

Next, we examined the dynamic relationship between stock market returns, oil market returns, stock market volatility and oil price volatility in the framework of a VAR model with only lagged values of the right-hand-side variables in each equation. The model is estimated by ordinary least squares (OLS), and executes Granger causality tests (Granger, 1969) by testing for zero restrictions on subsets of lagged parameters in each equation of the VAR in order to investigate lead-lag relationships between the variables in question (Chatrath, Ramchander and Song, 1995).

The formulation of the VAR model we used is presented below:

$$
\begin{aligned}
& D L S_{i}=a+\sum_{j=1}^{p} \beta_{j} D L S_{i-j}+\sum_{j=1}^{p} \gamma_{j} D_{L O P_{i-j}}+\sum_{j=1}^{p} \delta_{j} \operatorname{VAROIL}_{i-j} \sum_{j=1}^{p} z_{j} \operatorname{VARLS}_{i-j}+e_{i}(6) \\
& \operatorname{VARLS}_{i}=a+\sum_{j=1}^{p} \beta_{j} D L S_{i-j}+\sum_{j=1}^{p} \gamma_{j} \operatorname{DLOP}_{i-j} \sum_{j=1}^{p} \delta_{j} \operatorname{VAROIL}_{i-j}+\sum_{j=1}^{p} z_{j} \operatorname{VARLS}_{i-j}+e_{i}(7)
\end{aligned}
$$

where $\beta, \gamma, \delta$ and $\mathrm{z}$ are parameters, $\mathrm{p}$ is chosen on standard statistical grounds, and $\mathrm{e}_{\mathrm{i}}$ is a white noise error term. The lag length of the lagged group of variables was chosen equal to 12 and it was determined by means of Akaike Information Criteria.

Based on the estimates derived from equations (6) and (7), we performed Granger Causality Tests, in order to detect the possible existence and direction of the causal impacts between stock and oil markets. The results are presented in Table 3.

It should be noted that from the full SEM we report only equations for DLS and VARLS variables as, by common sense, we do not expect the Greek stock market and its volatility to cause any effect of significant magnitude on the oil price index and its volatility. In short, the findings support the existence of significant causal interactions between stock market and oil market. With regard to the direction of Granger causal effects (table 3 in the appendix), we find evidence of strong bi-directional causal effects between stock market returns and stock market volatility $(\mathrm{pv}<0.01)$. We also find positive significant causal effects running from oil price returns and oil price volatility ( $\mathrm{pv}=0.016$ and 0.015 respectively) towards the stock market returns. Last we detect positive causal impacts running from the volatility of oil price returns to stock market volatility.

The results obtained are consistent with Jones and Kaul (1996) who suggest that oil price shocks impact the stocks prices, Sadorsky (1999) who shows that oil price movements are important in explaining movements in the stock returns, and Papapetrou (2001) who finds a positive relationship between the two markets. Our results are possibly justified by the fact that oil companies participate heavily in the calculation of the General index in the ASE. Figure 2, in the Appendix, presents the almost parallel move of the oil price index and the Athens General Index from 8/2004 until 9/2006. A possible reason for this parallel movement may be the fact that two of the biggest oil companies, listed in the ASE, participate by more than 5\% at the Athens General Index. It should also be noted that the strong gains presented in the balance sheets of the oil companies in Greece affect directly or indirectly the corporate returns of various banks or funds that own shares in these companies. In turn, the increase of the stock prices of these banks or funds directly affect the general index.

We also find evidence that the volatility of oil price has significant positive causal impacts in the stock market returns as well as on stock market volatility. This may be attributed to the fact that Greek stock market is 
heavily dependent on oil companies, or companies which hold shares in oil companies. The volatility of the oil price has direct impact on the gains of these companies, and this is reflected on the stock market prices and the stock market volatility.

\section{CONCLUSION AND POLICY IMPLICATIONS}

We investigate the dynamic linkages between the Greek stock market returns and the oil price behaviour. Particularly, we explored the interactions among stock market returns, the volatility of the stock market index, the oil returns and the oil price index volatility. We employ a VAR model in conjunction with Granger-causality tests. Our findings support the existence of significant positive association between stock market and oil market. With regard to the detection of Granger causal effects, we find evidence of strong bi-directional causality between stock market returns and stock market volatility. We also find significant positive causal effects running from oil price index returns and oil price volatility towards the stock market returns. Finally, we detected causal impacts from the volatility of oil price on stock market volatility.

Our results have broad policy implications, relating to the business environment of the country. Companies should be ready to adjust to a new low oil price environment as a future oil price fall in a volatile environment is likely to lead to stock market fall. The period examined in this paper coincides with high levels of oil price. This is probably due to various incidents such as the Gulf war, the increased oil demand from China and India and the low oil reserves that have been reported by the U.S. government. It is likely that when these reasons cease to exist the oil price will fall. In such a case listed companies may find it hard to fund their expansion using collateral instruments such as their own stocks. On the other hand, when oil price increases, listed companies will benefit from the positive association between the oil price and the subsequent increase in their capitalization since they will be in position to use their high capitalisation as collateral. In that case unlisted companies do not benefit from the high oil price levels since their capitalization remains stable.

Therefore, policy makers should keep an eye on the effects of oil price movements on the stock market volatility and intervene, whenever is required, so as to ensure the stable and unaffected operation of the stock market with the broader objective of systemic financial stability in mind.

\subsection{Suggestions for Future research}

In the future, it would be interesting to analyze each stock that comprise the stock market index and examine the interactions among each stock, the volatility of the stock market index, the oil returns and the oil price index volatility. Taking a step further, a comparative research between emerged and emerging economies would reveal the different ways that the stock market reacts in each economy against the oil price returns and the oil price volatility. Moreover, it would be examined if every emerged or emerging economy reacts homogenously. Finally, it would be interesting to add and examine other variables such as the foreign exchange, the debt markets and the GDP.

\section{AUTHOR INFORMATION}

Dr. Constantinos Katrakilidis is currently Associate Professor of Econometrics at the Aristotle University of Thessaloniki, Department of Economics. He graduated and received his postgraduate diploma and doctoral degree from the Aristotle University of Thessaloniki and continued with post doctoral research at the KVL University of Kopenhagen, Denmark.

Dr.Katrkilidis has lectured extensively topics on theoretical and applied Econometrics at the Economics Department of the University of Thessaloniki as well as on Statistics and Operational Research at the Department of Accounting in Serres.

He has published several articles in recognized national and international journals (Atlantic Economic Jounal, Weltwirtschaftliches Archiv, International Review of Economics and Business, Economics and Business Review, International Journal of Economic Research, International Advances in Economic Research, Annals of Economics 
and Finance, Applied Economics Letters, Journal of Agricultural and Applied Economics, Agricultural Economics Review, Research in International Business and Finance, International Research Journal of Finance and Economics, Research Journal of International Studies and others) and has refereed for several journals (Agricultural Economics, Agricultural Economics Review, European Journal of Political Economy, Review of Economic Sciences and others).

Dr. Dimitris Mardas, is an Associate Professor, Department of Economics, Aristotle University of Thessaloniki. In the past worked Secretary General of Commerce, Ministry of Development (from 2000 to 2002), Managing Director of the Hellenic Export Promotion Organisation (HEPO) (from 2003 to 2004) and as National Detached Expert of the Commission of the EC (from 1992 to 1994).

He has recently published in Southeast European and Black Sea Studies, Transition Studies Review, Atlantic Economic Journal, Intenational Advances in Economic Research, Technovation and others.

Mr Andreas Ektor Lake is an applied econometrics $\mathrm{PhD}$ candidate at Aristotle University of Thessaloniki. He Holds an MSc Investment management from City University, CASS Business school. Currently he works as a FX options market maker at EFG Eurobank in Athens.

He has recently published in European Research Studies Journal, International Review of Applied Economic Research, International Journal of Economic Research and others. His work has been presented in the international Atlantic conference, the international Symposium on Applied stochastic Models and Data analysis, the International conference on recent developments in Economics, Finance, accounting and econometrics, the international conference on Applied Business and economics and others.

\section{REFERENCES}

1. Bopp, A. E., and S. Sitzer, Are petroleum futures prices good predictors of cash value?" Journal of Futures Markets, 7, 705-719, 1987.

2. Bolleserslev, T., Chou, R.Y. and Kroner, K.F, ARCH Modelling in Finance: A review of the Theory and Empirical Evidence. Journal of Econometrics 52(5), 5-59, 1992.

3. Chan K. and Chung P.Y, Intraday Relationships among Index Arbitrage, Spot and Futures Price Volatility, and Spot Market Volume: A transaction Data set", Journal of Banking and Finance, 17, 663-687, 1993.

4. $\quad$ Chatrath A., Ramchander S. and Song F, Does Options Trading Lead to Greater Cash Market Volatility?" Journal of Futures Markets, 15, 785-803,1995.

5. $\quad$ Fama, E. "The Behavior of Stock Market Prices", Journal of Business, vol. 38, 34-105, 1965.

6. Gisser, M. and T.H Goodwin, Crude oil and the macroeconomy: tests of some popular notions". Journal of Money, Credit and Bank, 18, 95- 103, 1986.

7. Hwang, M.J., Yang, C.W., Huang, B.N., and Ohta H, Oil Price Volatility." Encyclopedia of Energy, Volume 4, 691-699, 2004

8. Hamilton, J. D. Oil and the macroeconomy since World War II." Journal of Political Economy, 88: 829853,1983

9. Huang, R. D., R. W. Masulis, and H. R. Stoll, Energy shocks and financial markets." Journal of Futures Markets, 16:1-27, 1996

10. Granger C.W.I. Investigating Causal Relations by Econometric Models and Cross-Spectral Methods", Econometrica, 37, 423-438, 1969

11. Jones, C. M. and G. Kaul, "Oil and Stock Markets." Working Paper, University of Michigan, 1992

12. Jones, C.M., and Kaul, G, "Oil and Stock Markets" Journal of Finance 51 (2), 463-491, 1996

13. Lee, K., S. Ni, and R. A. Ratti, "Oil shocks and the macroeconomy: The role of price variability." Energy Journal, 16, 39-56, 1995

14. Loungani, P. "Oil price shocks and the dispersion hypothesis." Review of Economics and Statistics, 68, 536-539, 1986

15. Maghyereh, A. "Oil price shocks and the emerging stock markets: A generalized VAR approach." International Journal of Applied Econometrics and Quantitative Studies, 1-2, 27-40, 2004

16. Mandelbrot, B. "The Variation of Certain Speculative Prices", Journal of Business, 1963 
17. Mork, K. A. "Oil and the macroeconomy when prices go up and down: An extension of Hamilton's results." Journal of Political Economy, 91, 740-744, 1989

18. Mork, K. A., O. Olsen, and H. T. Mysen, "Macroeconomic responses to oil price increases and decreases in seven OECD countries." Energy Journal, 15, 19-35, 1994

19. Nelson, D. B. Conditional heteroskedasticity in asset returns: A new approach, Econometrica 59, 347-370, 1991

20. Papapetrou, E. “Oil Price Shocks, Stock Market, Economic Activity and Employment in Greece." Energy Economics, 23, 511-532, 2001

21. Sadorsky, P. "Oil price shocks and stock market activity." Energy Economics, 21, 449-469, 1999 


\section{APPENDIX}

Table 1

E-GARCH estimation results with the oil price variable (DLOP) as dependent

Exponential GARCH $(0,1)$ assuming a t distribution

Dependent variable is DLOP

Regressor

$\mathrm{C}$

Coefficient

$\operatorname{DLOP}(-6)$

DLOP(-12)

$\operatorname{DLOP}(-13)$

DLOP $(-19)$

DLOP $(-21)$

DUMOIL

R-Squared

S.E. of Regression

DW-statistic

Parameters of the Conditional Heteroscedastic Model

Explaining the Logarithm of H-SQ, the Conditional Variance of the Error Term

\begin{tabular}{ll}
\hline & Coefficient \\
Constant & -7.8622 \\
E/H)(- 1) & -.041930 \\
ABS(E/H)(- 1)-MEU & .064355 \\
D.F. of t-Dist. & 3.4623
\end{tabular}

ariance of the Error Term

$.7960 \mathrm{E}-3$

$-.050823$

$-.10948$

T-Ratio[Prob]

[.236]

$[.135]$

[.002 ]

[.104]

$[.038]$

[.400]

[.020]

$-.073257$

$-.14026$

$0.73908 \quad$ R-Bar-Squared $\quad 0.72716$

$\begin{array}{llll}0.73908 & \text { R-Bar-Squared } & 0.72716 & \\ 0.006974 & \text { F-stat } & F(9,197) & 62.0025[.000]\end{array}$

Asymptotic Standard Error
.18439
.002905
.015141
1.1046

Table 2

E-GARCH estimation results with the stock market variable (DLS) as dependent

\begin{tabular}{lll}
\hline \multicolumn{2}{l}{ Exponential GARCH$(0,1)$ assuming a distribution } & \\
\hline Regressor & Coefficient & T-Ratio[Prob] \\
C & $.6622 E-3$ & {$[.123]$} \\
DLS(-1) & .078515 & {$[.056]$} \\
DLS(-13) & .088346 & {$[.024]$} \\
DLS(-12) & -.046848 & {$[.185]$} \\
DLS(-15) & .059973 & {$[.123]$} \\
DLS(-16) & .09181 & {$[.024]$} \\
DLS(-17) & -.086122 & {$[.035]$} \\
DLS(-18) & .070130 & {$[.018]$} \\
DLS(-22) & -.083464 & {$[.036]$} \\
DUMOIL & .0030741 & {$[.423]$} \\
R-Squared & .61196 & .582295 \\
S.E. of Regression & .010076 & $\mathrm{~F}(11,558)$ \\
DW-statistic & 2.387 & \\
\hline Parameters of the Conditional Heteroscedastic Model & \\
Explaining the Logarithm of H-SQ, the Conditional Variance of the Error Term & \\
\hline & Coefficient & Asymptotic Standard Error \\
Constant & -9.2217 & 0.06373 \\
(E/H)(- 1) & -.016907 & .0060203 \\
ABS(E/H)(- 1)-MEU & .16079 & .077088
\end{tabular}

Table 3

Granger Causality Tests based on the SEM estimates (Wald $\mathbf{X}^{2}$ )

\begin{tabular}{|c|c|c|c|c|}
\hline Dependent Variable & DLS & VARLS & DLOP & VAROIL \\
\hline $\begin{array}{l}\text { DLS } \\
\text { VARLS }\end{array}$ & $0.000 *(-)$ & $0.000 *(-)$ & $\begin{array}{c}0.015 *(+) \\
0.302(+)\end{array}$ & $\begin{array}{l}0.016 *(+) \\
0.002 *(+)\end{array}$ \\
\hline
\end{tabular}


Figure 1

Oil price per barrel from 1970 until 2007 (Expressed in US \$)

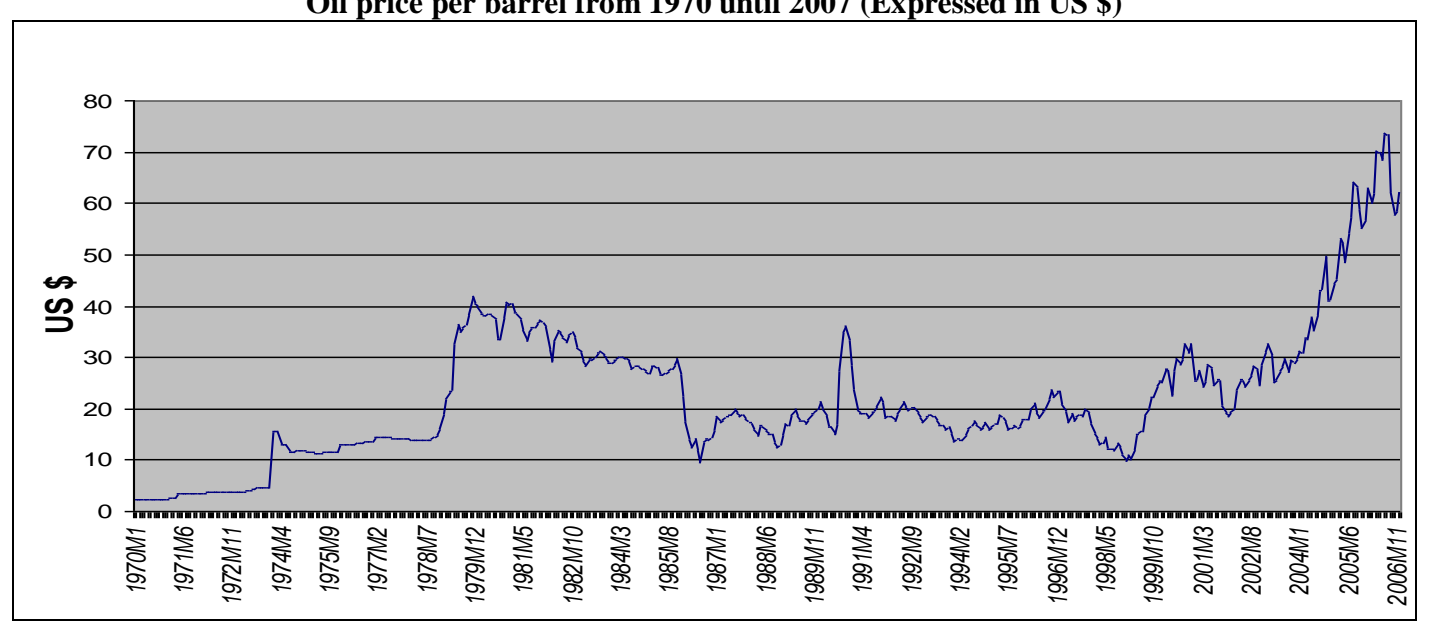

Figure 2

Oil price index and Athens General Stock Market Index

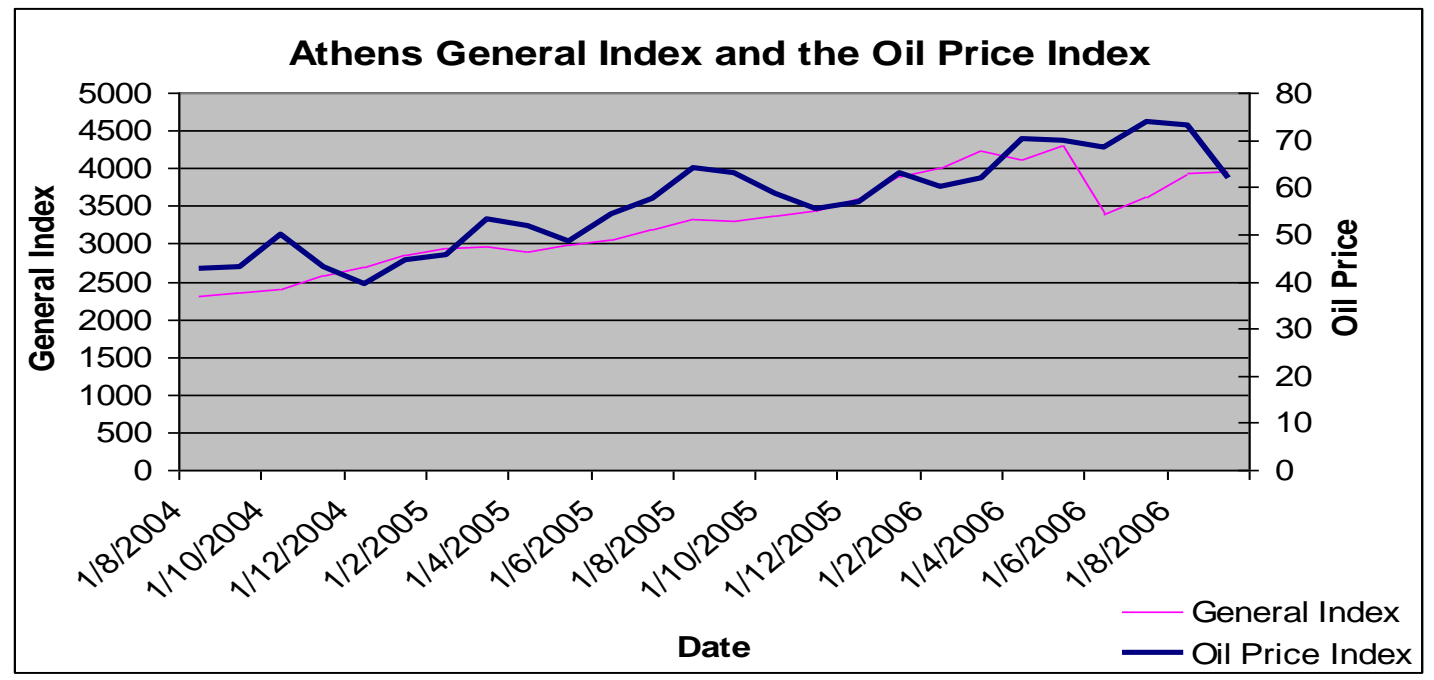




\section{NOTES}

